\title{
Scientific Ocean Drilling and Sedimentary Geoscience: Decades of Discovery and a Vision for the Future
}

\author{
Brian Romans ${ }^{1, *}$ \\ ${ }^{1}$ Department of Geosciences, Virginia Tech, Blacksburg, VA, USA
}

$\mathrm{R}^{\mathrm{e}}$ ecovering sediments and sedimentary rocks from below the seafloor is a familiar part of our science. However, it wasn't that long ago when the idea to retrieve sediment cores from beneath the deep ocean was a new and exciting technological achievement, as illustrated by the following excerpt from a 1982 book by Kenneth Hsü:

[One of the expedition scientists, Bill] Ryan was discouraged. He had invested some ten years of his professional life in studying the Mediterranean seabed with all manner of sophisticated geophysical gadgets. He knew there was some very strange rock down there, reflecting back all acoustic signals sent down. Now we had a drilling ship and could bore through the deep-sea floor. A sample, or even a small chip, of the rock might resolve his puzzlement.

Hsü's wonderful book, entitled The Mediterranean Was a Desert: A Voyage of the Glomar Challenger, chronicles a 1970 expedition as part of the new, at the time, Deep Sea Drilling Program (DSDP) and underscores the extraordinary value of getting cores and samples from difficult-to-access places. As useful as our geophysical and remote-sensing tools are, for many scientific questions and applications we need tangible samples and material. Planetary geologists know this feeling well in the context of the incredibly precious lunar samples and plans for returning samples from Mars in the near future. The early days of scientific ocean drilling (DSDP started in the late 1960s) were, in a sense, similar. The ability to recover bits of mud, sand, and rock from below the seabed-motivated primarily by scientific curiosity and discovery-revolutionized Earth science.

The successor programs to DSDP (1966-1983) came with different names and acronyms-Ocean Drilling Program (ODP; 1983-2003), Integrated Ocean Drilling Program (IODP; 2003-2013), and the current International Ocean

\footnotetext{
Copyright (c) 2021 by the SEPM Society for Sedimentary Geology

doi: $10.2110 /$ sedred.2021.3.1

*Corresponding author: romans@vt.edu
}

Discovery Program (IODP; 2013-2024) — and they collectively represent a continuous program of more than 50 years of scientific discovery.

The current IODP has multiple scientific themes and objectives, the majority of which require recovery and analysis of the sedimentary record to achieve. For example, the Climate and Ocean theme targets sedimentary archives for reconstructing past oceanographic change, and such records provide critical context for understanding contemporary climate change and its impacts on Earth systems. The themes that emphasize geohazards commonly tap into sediments for insights into, for example, megathrust earthquake recurrence and magnitude. It's estimated that approximately $70-75 \%$ of the drilling expeditions over the decades have targeted sediments or sedimentary rocks. And many of the drilling expeditions that have focused on oceanic crust or submarine volcanism ended up recovering valuable records from the veneer of sediment covering the primary scientific targets. The role of sedimentary geoscience, paleontology/paleobiology, marine geology, and other areas of interest to the SEPM community in the success of scientific ocean drilling cannot be understated.

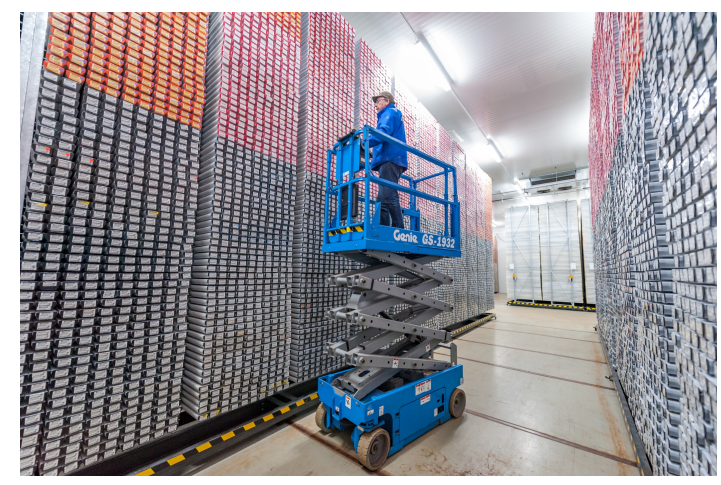

Figure 1: One row in one of the four IODP core repositories, where cores and samples from hundreds of expeditions going back several decades, are archived and available for the scientific community. 
One of the primary laboratory teams aboard the JOIDES Resolution, the workhouse vessel for scientific ocean drilling since 1985, is tasked with the initial characterization of cores as they are brought on deck. This team is commonly referred to simply as the "sedimentology" lab. While the JOIDES Resolution (or 'JR' for short) and other IODP vessels and coring systems are continuously updated with state-of-the-art instrumentation, the fundamental work is done by sedimentary geoscientists and micropaleontologists using tried-and-true observational skills. The enduring value of scientific ocean drilling is the linkage of shipboard descriptions and data with the archived cores themselves.

IODP and it's legacy programs have been operating continuously for so long that it may seem that scientific ocean drilling is a permanent fixture of Earth science. The SEPM community has benefited from these programs in a variety of ways: data and materials used in our education and outreach, student research projects involving legacy cores, direct involvement through development and participation in new drilling expeditions, and much more. However, the stability of scientific ocean drilling should not be taken for granted. Each of the 10-15 years-long programs required significant effort from the scientific community to propose, develop, and maintain. First and foremost are the scientific objectives: What are the highest-priority Earth science questions and problems that ocean drilling can help answer or solve? These community-developed science objectives are the plans that the funding agencies of participating nations use to make decisions regarding financial and infrastructural support.

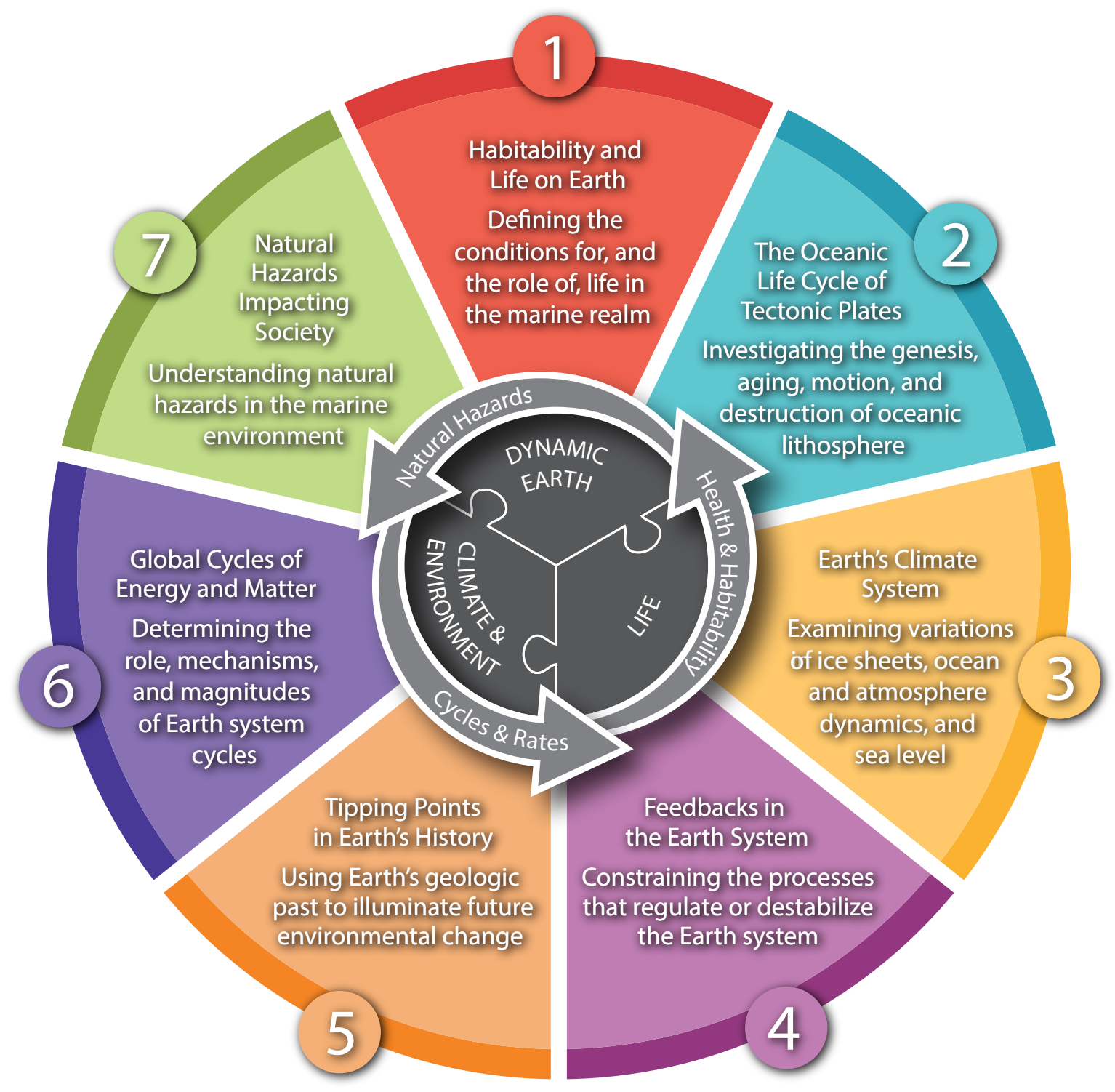

Figure 2: The 2050 Science Framework document includes seven Strategic Objectives, which emphasize the interconnections of the Earth system. 


\section{FRAMEWORK FOR THE FUTURE OF OCEAN DRILLING}

In late 2019 and into 2020, an international and multidisciplinary team of editors, writers (of which I was one), and reviewers were tasked with generating a document that aims to make the case for scientific ocean drilling to continue into the future. Ideas and feedback from the broader scientific ocean drilling community were gathered by various mechanisms, including several workshops organized and led by groups in sponsoring countries. The outcome of these efforts is the 2050 Science Framervork: Exploring Earth by Scientific Ocean Drilling document, which was released in October 2020. This document is distinct from historical IODP efforts in that it's not a science plan for just the next decade of ocean drilling. Rather, the 2050 Science Framework is designed to provide guidance to current and future generations of ocean drilling scientists about research objectives and directions for multiple decades into the future. The 2050 Science Framework calls for strong collaboration among Earth science disciplines to meet science goals and enhance communication of results to a broad global audience.

The 2050 Science Framework communicates several Strategic Objectives that are inherently multidisciplinary and cut across the traditional themes of previous scientific ocean drilling efforts. These objectives are, by design, openended and include: (1) Habitability and Life on Earth, (2) The Oceanic Life Cycle of Tectonic Plates, (3) Earth's Climate System, (4) Feedbacks in the Earth System, (5) Tipping Points in Earth's History, (6) Global Cycles of Energy and Matter, and (7) Natural Hazards Impacting Society. Each of these objectives emphasizes understanding interconnections, both with the broader Earth system and among the other objectives. The research, education, and outreach interests of the SEPM community are embedded in all of these objectives to varying degrees.

In addition to the Strategic Objectives, the 2050 Science Framework includes five broad Earth science research efforts that will require coordinated and sustained efforts over appreciable time to accomplish (e.g., multi-expedition drilling initiatives over 10- to 20-year intervals). These Flagship Initiatives include: (1) Ground Truthing Future Climate Change, (2) Probing the Deep Earth, (3) Assessing Earthquake and Tsunami Hazards, (4) Diagnosing Ocean Health, and (5) Exploring Life and Its Origins. These initiatives combine research goals outlined in and that overlap with the Strategic Objectives. Most of the Flagship Initiatives involve research areas of the SEPM community in a direct and fundamental way.

Finally, the 2050 Science Framework document discusses the numerous aspects of scientific ocean drilling associated with how this type of collaborative science is done, the interactions between research and education, and a forward-looking approach to broadening participation and maximizing the impact to society. The document outlines several important aspects including: broader impacts and research, open access to samples and data, bottom-up proposal submissions and peer review, technology development and big data analytics, collaborative and inclusive international programs, and enhancing diversity in the ocean drilling community, to name a few.

\section{WHAT CAN THE SEPM COMMUNITY DO TO SUPPORT THE FUTURE OF SCIENTIFIC OCEAN DRILLING?}

First and foremost, get familiar with the 2050 Science Framework document; it is comprehensive (120 pages) while maintaining stand-alone sections, includes spectacular illustrations, and aims to tie together numerous aspects of sedimentary geosciences. SEPM members that have been involved with scientific ocean drilling will find both familiar and new ideas in the 2050 Science Framework, whereas those who have not been involved in ocean drilling will find value in the breadth and scope of the Earth science research, education, outreach, technology development, and international collaboration envisioned. For those whose

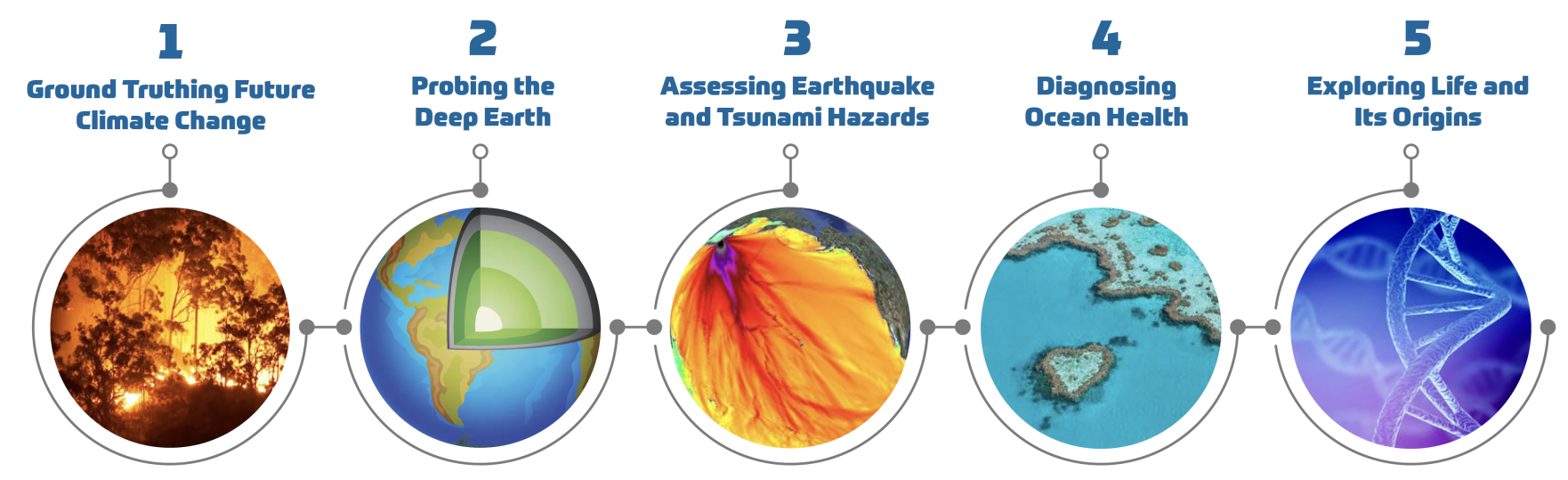

Figure 3: The 2050 Science Framework document includes five Flagship Initiatives identified by the broader community as important Earth science research that will require multi-expedition drilling efforts over 10 - to 20 -year time intervals. 


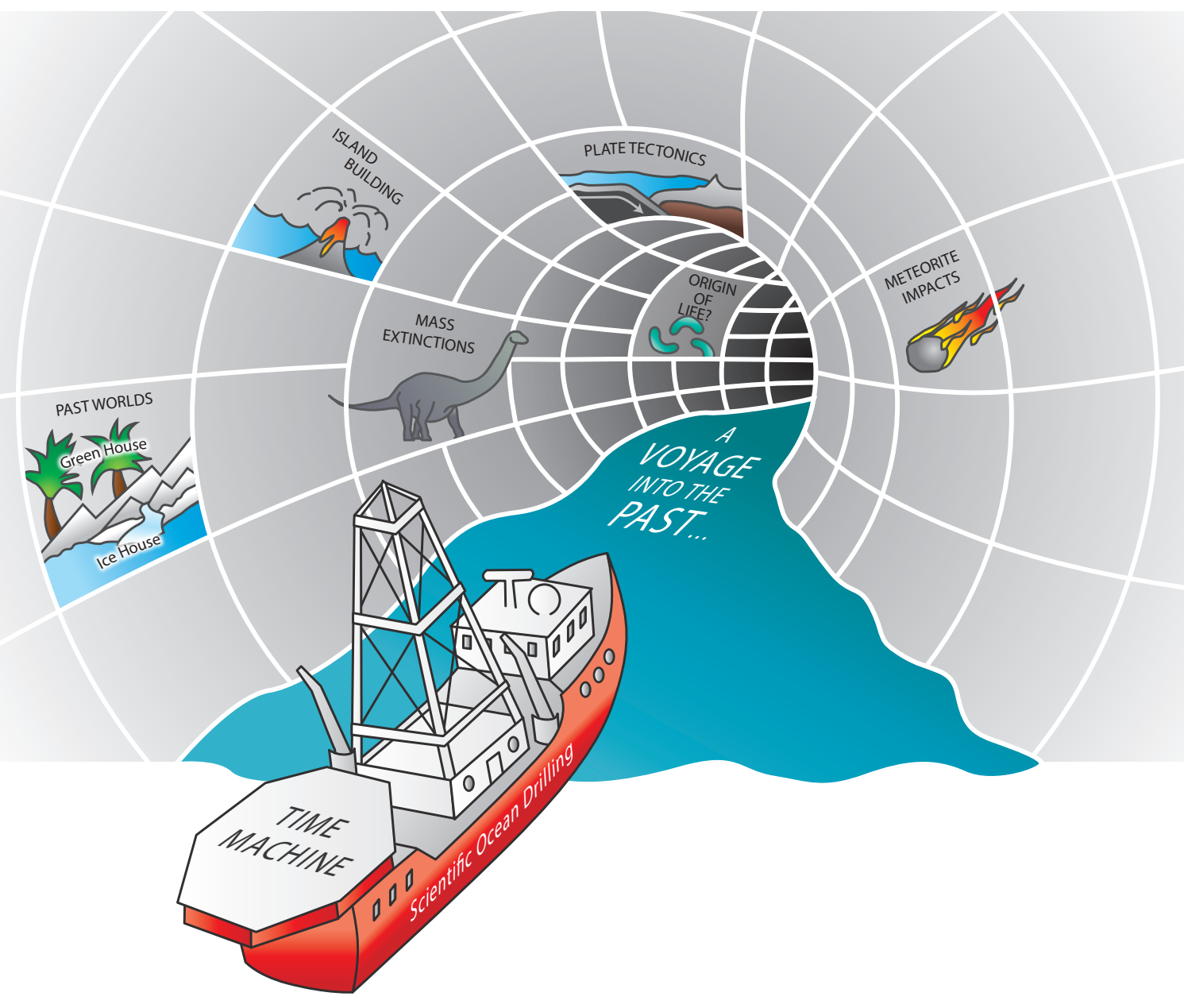

Figure 4: Drilling into and recovering the sedimentary record can be framed as a voyage to the past, with the drilling vessel itself described as a 'time machine'. More and improved science communication about scientific ocean drilling to non-specialists can enhance the excitement about SEPM community science.

research has not involved ocean drilling cores and/or data up to this point, consider how the questions and problems of interest could be addressed through the collaborative and 'big science' endeavor that is ocean drilling.

Participating in scientific ocean drilling does not require going to sea or proposing new drilling expeditions. A key aspect of the program is sustaining the archive of cores and shipboard data that are available to the scientific community. Requesting samples from DSDP, ODP, and IODP cores is a straightforward and streamlined process and, if you cannot travel to the repository to sample yourself, IODP curators will do it for you and ship the samples directly to you. The scientific ocean drilling community and program wants the broader Earth science community to use this material to help generate new knowledge and make discoveries about our planet. Ultimately, the continuation of this incredibly successful Earth science program amplifies the important role of sedimentary geoscience, paleontology/paleobiology, and related fields that are relevant to the SEPM community.

\section{ACKNOWLEDGMENTS}

The figures and parts of the text are from:

KOPPERS, A.A.P., and R. COGGON, eds. 2020. Exploring Earth by Scientific Ocean Drilling: 2050 Science Framework. 124 pp., https://doi.org/10.6075/J0W66J9H.

Figure 1: MARUM - Zentrum für Marine Umweltwissenschaften; Universität Bremen; V. Diekamp.

Figure 2: Developed by the 2050 Science Framework writing team with input from the IODP community and designed by Ellen Kapal and Johanna Adams (Geosciences Professional Services, Inc.).

Figure 3: Designed by Johanna Adams and Ellen Kapal (Geosciences Professional Services, Inc.).

Figure 4: Illustration by 2050 Science Framework coeditor Rosalind Coggon. 